\title{
New insulin delivery devices and glycemic outcomes in young patients with type 1 diabetes: a protocol for a systematic review and meta-analysis
}

Tiago Jeronimo Dos Santos ${ }^{1,2^{*}}$ D, Juan de Mata Donado Campos ${ }^{1,3}$, Cristina Alexandra Fraga Medin ${ }^{4}$, Jesús Argente $2,5,6,7$ and Fernando Rodríguez-Artalejo ${ }^{1,3,7}$

\begin{abstract}
Background: Optimal type 1 diabetes mellitus (T1D) care requires lifelong appropriate insulin treatment, which can be provided either by multiple daily injections (MDI) of insulin or by continuous subcutaneous insulin infusion (CSII). An increasing number of trials and previous systematic reviews and meta-analyses (SRMA) have compared both CSII and MDI but have provided limited information on equity and fairness regarding access to, and the effect of, those insulin devices. This study protocol proposes a clear and transparent methodology for conducting a SRMA of the literature (1) to assess the effect of CSII versus MDI on glycemic and patient-reported outcomes (PROs) among young patients with T1D and (2) to identify health inequalities in the use of CSII.

Methods: This protocol was developed based on the Preferred Reporting Items for Systematic Reviews and MetaAnalysis Protocols (PRISMA-P), the PRISMA-E (PRISMA-Equity 2012 Guidelines), and the Cochrane Collaboration Handbook. We will include randomized clinical trials and non-randomized studies published between January 2000 and June 2019 to assess the effectiveness of CSII versus MDI on glycemic and PROs in young patients with T1D. To assess health inequality among those who received CSII, we will use the PROGRESS framework. To gather relevant studies, a search will be conducted in MEDLINE, EMBASE, Cochrane Central Register of Controlled Trials (CENTRAL), the Cochrane Database of Systematic Reviews, and the Health Technology Assessment (HTA) database. We will select studies that compared glycemic outcomes (the glycosylated hemoglobin values, severe hypoglycemia episodes, diabetic ketoacidosis events, and/or time spent in range or in hyper-hypoglycemia), and health-related quality of life, as a PRO, between therapies. Screening and selection of studies will be conducted independently by two researchers. Subgroup analyses will be performed according to age group, length of follow-up, and the use of adjunctive technological therapies that might influence glycemic outcomes.
\end{abstract}

Discussion: Studies of the average effects of CSII versus MDI may have not assessed their impact on health equity, as some intended populations have been excluded. Therefore, this study will address health equity issues when assessing effects of CSII. The results will be published in a peer-review journal. Ethics approval will not be needed.

Systematic review registration: PROSPERO CRD42018116474

Keywords: Insulin pump, Continuous subcutaneous insulin infusion, Multiple daily injections, Health inequity, Type 1 diabetes

\footnotetext{
* Correspondence: tiagojer@gmail.com

${ }^{1}$ Department of Preventive Medicine and Public Health. School of Medicine,

Universidad Autónoma de Madrid/IdiPAZ, Madrid, Spain

${ }^{2}$ Departments of Pediatrics \& Pediatric Endocrinology, Hospital Infantil

Universitario Niño Jesús. Research Institute "La Princesa", Madrid, Spain

Full list of author information is available at the end of the article
}

(c) The Author(s). 2019 Open Access This article is distributed under the terms of the Creative Commons Attribution 4.0 International License (http://creativecommons.org/licenses/by/4.0/), which permits unrestricted use, distribution, and reproduction in any medium, provided you give appropriate credit to the original author(s) and the source, provide a link to the Creative Commons license, and indicate if changes were made. The Creative Commons Public Domain Dedication waiver (http://creativecommons.org/publicdomain/zero/1.0/) applies to the data made available in this article, unless otherwise stated. 


\section{Background}

Optimal type 1 diabetes mellitus (T1D) care requires lifelong appropriate insulin treatment that can be provided by either multiple daily injections (MDI) of insulin or by a continuous subcutaneous insulin infusion (CSII) pump [1]. Over the last years, the use of CSII has increased substantially among pediatric patients [1]. However, the selection of CSII versus MDI might have not been based only on clinical indications (e.g., elevated glycosylated hemoglobin and higher hypoglycemia rate), but also could have been influenced by social factors, such as the place of residence and socioeconomic status, which may have led to health inequalities [1-3].

Meeting glycemic targets is a challenging task in young patients with T1D; thus, new insulin delivery systems represent an opportunity to improve glycemic control, to promote patient-centered decisions, and to reduce the burden of diabetes care $[4,5]$. Although an increasing number of trials has assessed whether the CSII is more effective than the intensive insulin therapy with syringe and/or pen [6-13], previous systematic reviews and meta-analyses (SRMA) of trials have not reported adequate information concerning equity and fairness in treatment selection [14-17].

Given the greater difficulty for good glycemic control in patients/families with lower health literacy and poor access to some healthcare resources, it is possible that the absolute benefit of CSII would be greater in those with lower socioeconomic status [18]. However, we do not know if they have the chance to participate and benefit from this intervention. In addition, there might exist several barriers for patient access and/or maintenance using CSII, and only a few studies (e.g., diabetes registries) have investigated the role of unequal health care access and social disparities on glycemic outcomes $[2,19,20]$. In consequence, SRMAs with an equity lens could assess whether unequal benefits across sociodemographic population groups could contribute to worsening health inequalities in T1D management [21-23].

Therefore, this paper aims to report a standardized and transparent methodology for conducting a SRMA of the literature (1) to assess the effectiveness of using CSII versus MDI on glycemic (glycosylated hemoglobin, severe hypoglycemia, diabetes ketoacidosis and glycemic variability) and patient-related outcomes among young patients with T1D and (2) to identify health inequalities for those who use CSII.

\section{Methods}

\section{Review design}

This protocol was developed based on the Preferred Reporting Items for Systematic Reviews and MetaAnalysis Protocols (PRISMA-P) [24] and was registered and published on PROSPERO international prospective register of systematic reviews (registration number CRD42018116474). The Cochrane Collaboration Handbook [25] will also be used to guide the review methods, and PRISMA-E (PRISMA-Equity 2012) Guidelines [26] to elaborate the final report. To perform the SRMA, we will include randomized clinical trials (RCT) and nonrandomized studies (NRS) - which cover diabetes registries and longitudinal studies-that compared the clinical effectiveness of CSII versus MDI in youths with T1D.

\section{Data sources and search strategy}

The bibliographic search will be conducted from January 2000 to June 2019 in MEDLINE (via PubMed), EMBASE, Cochrane Central Register of Controlled Trials (CENTRAL), the Cochrane Database of Systematic Reviews, and the Health Technology Assessment (HTA) Database. We will also carry out a handsearch of the previous reviews and the bibliography from the original articles for additional references, as well as of the gray literature focusing on abstracts from diabetes associations and conference proceedings, and from technical reports (research and governmental agencies). Search will use standardized subject terms and will be conducted by a librarian with the input from the principal investigator, using Boolean operators for MEDLINE, EMBASE, CENTRAL, and HTA database. The final search strategy will have no restrictions based on language or publication status (see Additional file 1).

\section{Eligibility criteria}

We will select studies that compared the use of CSII with MDI and evaluated any of the following glycemic outcomes: glycosylated hemoglobin $\left(\mathrm{HbA}_{1 \mathrm{c}}\right.$, percentage), the incidence of hypoglycemia episodes [e.g., severe, serious and/or nocturnal], diabetic ketoacidosis (DKA) events, and/or time spent in range or in hyper-hypoglycemia. Studies that mentioned health-related quality of life (HRQoL) as a PRO will also be selected. Specifically, the studies must meet the following selection criteria: (1) to be conducted with children and adolescents (under 20 years of age), (2) exclusively on patients with T1D, (3) designed as RCT or NRS, and (4) to have reported any of the outcomes of interest: $\mathrm{HbA}_{1 \mathrm{c}}$, hypoglycemia, DKA, time in range or in hyper-hypoglycemia, and HRQoL. Bihormonal or dual-hormone closed-loop systems that deliver glucagon in addition to insulin will not be included.

\section{Equity analysis}

To explore equity in CSII, we will use indicators of social disadvantages defined by PROGRESS [27]. The acronym PROGRESS is a framework to guide data extraction to relate the outcomes with equity of access to an intervention, according to "place of residence" (residing in a high- or low-to-middle-income country, as per the 
World Bank database), "race, ethnicity, culture and language" (racial, ethnical, and cultural background, when the majority of the groups include belonging to a distinctive group who shares origin, culture, traditions, and language through generations), "occupation" (parental patterns of work that favor proper maintenance of a therapy or not), "gender/sex" (sex refers to identify sex distribution when recommended each therapy), "religion" (religious affiliation, spiritual beliefs, or values that promote better access to health services), "education" (assumes that high parental educational level, or health literacy and numeracy, is an advantage), "socioeconomic status" (access to resources and privilege with greater household wealth, as an advantage), and "social capital" (benefits obtained by individuals due to their social relationships, as an advantage).

For each factor of inequality, we hypothesized different social gradients: (1) a positive gradient, when better glycemic outcomes are found in more socially advantaged groups; (2) a negative gradient, when better outcomes are found in less advantaged groups; and (3) a neutral gradient, when no significant differences exist between groups. The results will be summarized with the aid of a harvest plot, which is a graphical technique that helps to illustrate a narrative synthesis [28].

\section{Study selection and data extraction}

Two reviewers will work independently to check eligibility of studies (title and abstract and, if needed, full-text) and extract the appropriate information in full-text articles. Disagreements will be resolved by consensus. Assessment of eligibility and its inclusion will be conducted according to the indications of the PRISMA statement. Data to be extracted from articles include the year of publication, country, study design and period of data collection, baseline characteristics of participants, interventions and comparators, factors of inequalities at baseline, and outcomes (Tables 1 and 2).

The glycemic endpoints include (1) the mean value of $\mathrm{HbA}_{1 \mathrm{c}}$ (percentage), assessed preferably at the end of the study, (2) the number of serious, severe and/or nocturnal hypoglycemia episodes $[\leq 3.0 \mathrm{mmol} / \mathrm{L}$ ( 54 $\mathrm{mg} / \mathrm{dL}$ ) or an event associated with severe cognitive impairment (including coma and convulsions) requiring assistance], (3) the number of patients with $\geq 1$ DKA event, and (4) the percentage of time spent in range [percentage of readings in the glycemic range of $3.9-10.0 \mathrm{mmol} / \mathrm{L}(70-180 \mathrm{mg} / \mathrm{dL})$ per unit of time] or in hypo $[<3.9 \mathrm{mmol} / \mathrm{L}(<70 \mathrm{mg} / \mathrm{dL})]$ and hyperglycemia [ $>10 \mathrm{mmol} / \mathrm{L}(>180 \mathrm{mg} / \mathrm{dL})][23,29-32]$. PRO will be captured with the HRQoL questionnaires. When necessary, authors of eligible studies will be contacted to provide additional information.

\section{Assessment of risk of bias}

Two reviewers will independently assess the risk of bias of each study using two different tools: the Cochrane Risk of Bias form RCT and the RTI Item Bank for NRS [33, 34]. A review of only RCT may provide insufficient information on vulnerable subpopulations. Still, the inclusion of NRS may increase the challenges in establishing causal inference because they are at greater risk of bias than RCT, resulting from confounding by indication and selection bias. In contrast, threats to validity from performance and detection bias, and to precision from the inadequate sample size, should not differ markedly between RCT and NRS (although some features such as blinding of assessors that protect against detection bias are more likely in experimental designs than in observational studies). By including NRS (mainly registries), we may capture valuable information on the intended population for whom CSII is preferred, because registries are larger, studied over a longer time, and may better reflect all subgroups of patients and routine clinical practice [3].

\section{Statistical analysis}

We will summarize the main characteristics of selected studies, including the study's objectives and design, characteristics of study participants, intervention and comparator, inclusion of PROGRESS categories, and outcomes (Tables 1 and 2). Effects across the studies will be summarized with (1) the pooled mean difference for $\mathrm{HbA}_{1 \mathrm{c}}$; (2) the pooled rate ratio for hypoglycemia; (3) the pooled risk ratio for DKA; (4) the mean difference in percentage of time that blood glucose concentration remained in target range, in hypo- or in hyperglycemia; and (5) the pooled standardized mean difference (SMD) for quality of life outcomes, with their 95\% confidence interval $(\mathrm{CI})$, calculated with inverse variance random effects models to incorporate the level of heterogeneity found across studies [25, 35]. The effect size of the SMD will be classified as small (0.1-0.3), medium (0.3-0.6) or large $(\geq 0.6)$ [36]. Heterogeneity among studies will be assessed with the $I^{2}$ statistic, whose values will be classified as follows: no relevant heterogeneity $(0-25 \%)$, moderate heterogeneity (25$50 \%)$, and substantial heterogeneity (>50\%) [37]. Meta-analyses will be performed separately for RCTs and NRS when data are available for at least two studies with comparable results. For equity outcomes, results will be summarized as a narrative synthesis [28]. Publication bias will be evaluated graphically using a funnel plot and also with the method of Egger et al. [37]. The strength of the 


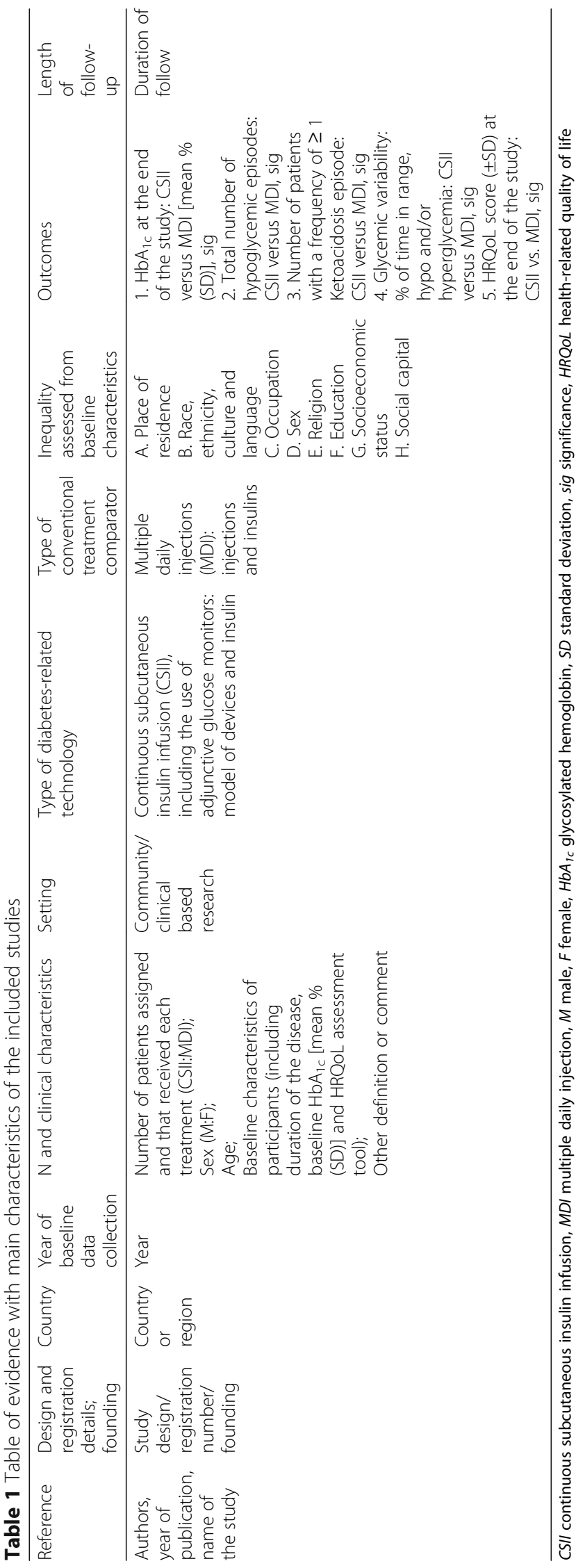


Table 2 PROGRESS framework to guide health equity data extraction on type 1 diabetes

\begin{tabular}{|c|c|c|c|}
\hline \multirow{2}{*}{ PROGRESS framework } & \multicolumn{3}{|c|}{ Social gradient } \\
\hline & Positive & Negative & Neutral \\
\hline $\begin{array}{l}\text { Place of residence: Country } \\
\text { where individuals reside (as per the } \\
\text { World Bank database). }\end{array}$ & $\begin{array}{l}\text { To reside in a high } \\
\text { income country }\end{array}$ & $\begin{array}{l}\text { To reside in a low-to- } \\
\text { middle income country }\end{array}$ & $\begin{array}{l}\text { No matter the place } \\
\text { of residence, } \\
\text { outcomes are non- } \\
\text { significant }\end{array}$ \\
\hline $\begin{array}{l}\text { Race, ethnicity, culture and } \\
\text { language: Self-identification racial or } \\
\text { ethnic group, or different culture and } \\
\text { language, including nationality status. }\end{array}$ & $\begin{array}{l}\text { To be a based-country } \\
\text { language } \\
\text { comprehension } \\
\text { inhabitant or to be part } \\
\text { of an ethnic majority }\end{array}$ & $\begin{array}{l}\text { To be part of minority } \\
\text { groups or to be a } \\
\text { foreign with low } \\
\text { language } \\
\text { comprehension }\end{array}$ & $\begin{array}{l}\text { No matter the race } \\
\text { or ethnic group, } \\
\text { outcomes are non- } \\
\text { significant }\end{array}$ \\
\hline $\begin{array}{l}\text { Occupation: Patterns of work } \\
\text { that provide proper maintenance of a } \\
\text { treatment. }\end{array}$ & $\begin{array}{l}\text { Affordability to have } \\
\text { access and maintain } \\
\text { technological devices }\end{array}$ & $\begin{array}{l}\text { No affordability to have } \\
\text { access and maintain } \\
\text { technological devices }\end{array}$ & $\begin{array}{l}\text { No matter the } \\
\text { parental occupancy } \\
\text { status, outcomes } \\
\text { are non-significant }\end{array}$ \\
\hline $\begin{array}{l}\text { "ேে Gender/Sex: Boys and girls } \\
\text { were identified between groups. }\end{array}$ & $\begin{array}{l}\text { Characterization of } \\
\text { sex distribution } \\
\text { between therapies; } \\
\text { girls are related to } \\
\text { belonging to an } \\
\text { advantaged group }\end{array}$ & $\begin{array}{l}\text { No characterization of } \\
\text { sex distribution } \\
\text { between therapies; } \\
\text { boys are related to } \\
\text { belonging to a } \\
\text { disadvantaged group }\end{array}$ & $\begin{array}{l}\text { No matter the sex } \\
\text { distribution, } \\
\text { outcomes are non- } \\
\text { significant }\end{array}$ \\
\hline $\begin{array}{l}\text { Religion: Religious affiliation } \\
\text { of spiritual beliefs or values. }\end{array}$ & $\begin{array}{l}\text { Access to health } \\
\text { services is favored for } \\
\text { a subgroup because } \\
\text { of its religious } \\
\text { affiliation or beliefs }\end{array}$ & $\begin{array}{l}\text { Access to health } \\
\text { services is limited } \\
\text { because } \\
\text { of its religious } \\
\text { affiliation or beliefs or } \\
\text { due to the lack of } \\
\text { religion }\end{array}$ & $\begin{array}{l}\text { No matter the } \\
\text { religion or beliefs, } \\
\text { outcomes are non- } \\
\text { significant }\end{array}$ \\
\hline $\begin{array}{l}\text { Education: Assessed by the } \\
\text { informed educational level or } \\
\text { approximated by health literacy and } \\
\text { numeracy. }\end{array}$ & $\begin{array}{l}\text { High educational level } \\
\text { or health literacy and } \\
\text { numeracy are } \\
\text { considered } \\
\text { advantaged group }\end{array}$ & $\begin{array}{l}\text { Low educational level } \\
\text { or health literacy and } \\
\text { numeracy are } \\
\text { considered } \\
\text { disadvantaged group }\end{array}$ & $\begin{array}{l}\text { No matter the } \\
\text { education, } \\
\text { outcomes are non- } \\
\text { significant }\end{array}$ \\
\hline $\begin{array}{l}\text { (ffen Socioeconomic status } \\
\text { (SES): To obtain information } \\
\text { considering access to resources and } \\
\text { privilege. }\end{array}$ & $\begin{array}{l}\text { A higher household } \\
\text { wealth is considered } \\
\text { advantaged group }\end{array}$ & $\begin{array}{l}\text { A lower familial income } \\
\text { is considered } \\
\text { disadvantaged group }\end{array}$ & $\begin{array}{c}\text { No matter the SES, } \\
\text { outcomes are non- } \\
\text { significant }\end{array}$ \\
\hline $\begin{array}{l}3.83 \\
\text { obtained by individuals due to their } \\
\text { social relationships, e.g.: to be } \\
\text { member of a diabetes foundation, to } \\
\text { participate in diabetes camp. }\end{array}$ & $\begin{array}{l}\text { To have network } \\
\text { involvement }\end{array}$ & $\begin{array}{l}\text { Not to have network } \\
\text { involvement }\end{array}$ & $\begin{array}{l}\text { No matter the } \\
\text { network } \\
\text { involvement, } \\
\text { outcomes are non- } \\
\text { significant }\end{array}$ \\
\hline
\end{tabular}

body of evidence will be assessed using the Grading of Recommendations Assessment, Development and Evaluation (GRADE) tool [38].
Subgroup analysis

Subgroup analyses will be performed based on age group, length of follow-up, and the use of adjunctive 
technological therapies that might directly improve glycemic outcomes.

\section{Sensitivity analysis}

The analyses will be repeated after exclusion of studies with a high risk of bias, and separately for RCT and NRS.

\section{Discussion}

Given the increase of worldwide incidence of T1D, the wider use of the CSII pump among some specific socioeconomic and demographic groups, and the lack of evidence of its superiority when compared with the conventional therapy using MDI, there is a need to critically assess the rise of inequalities in treatment selection [39]. Furthermore, the inclusion of PRO captured by health-related quality of life questionnaires will contribute to a complete diabetes measures portfolio [40]. Hence, the assessment of the effects of CSII versus MDI on glycemic outcomes, across social factors defined by PROGRESS, may contribute better to understand their impact on health equity $[12,16,41,42]$.

A major issue will probably be the limited data reported in the reviewed studies on the PROGRESS factors. For this reason, supplementary information will also be gathered from authors of the included studies. We are aware that the lack of important published information on equity may be a limitation of our review.

The results of an equity-oriented SRMA may yield an opportunity to discuss not only the effects of such interventions on glycemic endpoints, but also the existing gap of information in the included studies regarding social inequities; it will pave the way to use those results to orient clinical practice, equity-based research, and health policy formulation.

\section{Supplementary information}

Supplementary information accompanies this paper at https://doi.org/10. 1186/s13643-019-1171-9.

Additional file 1. Search Strategies

\footnotetext{
Abbreviations

CSII: Continuous subcutaneous insulin infusion; DKA: Diabetes ketoacidosis; GRADE: Grading of Recommendations Assessment, Development and Evaluation; $\mathrm{HbA}_{1 c}$ : Glycosylated hemoglobin; HRQoL: Health-related quality of life; HTA: Health Technology Assessment; MDI: Multiple daily injections; NRS: Non-randomized studies; PRISMA-E: Preferred Reporting Items for Systematic Reviews and Meta-Analysis - Equity Report; PRISMA-P: Preferred Reporting Items for Systematic Reviews and Meta-Analysis Protocols; PRO: Patient-related outcome; PROGRESS: Place of residence, race/ethnicity/ culture/language, occupation, gender/sex, religion, education, socioeconomic status, and social capital; RCT: Pandomized clinical trials; SMD: Standardized mean difference; SRMA: Systematic review and metaanalysis; T1D: Type 1 diabetes mellitus
}

\section{Authors' contributions}

TJ was responsible for the conception and design of the study. FRA and JA were the principal investigators and guarantors. CAFM prepared the search strategy. TJ and JDC selected the articles, extracted the data, and conducted the statistical analyses. TJ drafted the manuscript with the support of JA and FRA. All authors revised this work for important intellectual content, and approved the final manuscript.

\section{Authors' information}

TJ is a member of the International Society for Pediatric and Adolescent Diabetes (ISPAD) and the European Society for Paediatric Endocrinology (ESPE). JA is a member of the European Society for Paediatric Endocrinology (ESPE) and the Endocrine Society.

\section{Funding}

No funding

\section{Availability of data and materials}

Not applicable

Ethics approval and consent to participate

Not applicable

\section{Consent for publication}

The authors consent for further publication.

\section{Competing interests}

The authors declare that they have no competing interests.

\section{Author details}

${ }^{1}$ Department of Preventive Medicine and Public Health. School of Medicine, Universidad Autónoma de Madrid/IdiPAZ, Madrid, Spain. ²Departments of Pediatrics \& Pediatric Endocrinology, Hospital Infantil Universitario Niño Jesús. Research Institute "La Princesa", Madrid, Spain. ${ }^{3}$ Centro de Investigación Biomédica en Red de Epidemiología y Salud Pública (CIBERESP), Instituto de Salud Carlos III, Madrid, Spain. ${ }^{4}$ Biblioteca Nacional de Ciencias de la Salud, Instituto de Salud Carlos III, Madrid, Spain. ${ }^{5}$ Department of Pediatrics. School of Medicine, Universidad Autónoma de Madrid, Madrid, Spain. ${ }^{6}$ Centro de Investigación Biomédica en Red de Obesidad y Nutrición (CIBEROBN), Instituto de Salud Carlos III, Madrid, Spain. ${ }^{7}$ IMDEA Food Institute, CEIUAM+CSI, Madrid, Spain.

Received: 7 March 2019 Accepted: 27 September 2019

Published online: 04 November 2019

\section{References}

1. Danne T, Bangstad H-J, Deeb L, Jarosz-Chobot P, Mungaie L, Saboo B, et al. Insulin treatment in children and adolescents with diabetes. Pediatr Diabetes. 2014;15(S20):115-34.

2. Lin MH, Connor CG, Ruedy KJ, Beck RW, Kollman C, Buckingham B, et al. Race, socioeconomic status, and treatment center are associated with insulin pump therapy in youth in the first year following diagnosis of type 1 diabetes. Diabetes Technol Ther. 2013;15(11):929-34.

3. Pickup JC. The evidence base for diabetes technology: appropriate and inappropriate meta-analysis. J Diabetes Sci Technol. 2013;7(6):1567-74.

4. Wood JR, Miller KM, Maahs DM, Beck RW, Dimeglio LA, Libman IM, et al. Most youth with type 1 diabetes in the T1D exchange clinic registry do not meet American diabetes association or international society for pediatric and adolescent diabetes clinical guidelines. Diabetes Care. 2013;36(7):2035-7.

5. Tauschmann M, Hovorka R. Technology in the management of type 1 diabetes mellitus-current status and future prospects. Nat Rev Endocrinol. 2018;14(8):464-75.

6. Cohen D, Weintrob N, Benzaquen H, Galatzer A, Fayman G, Phillip M. Continuous subcutaneous insulin infusion versus multiple daily injections in adolescents with type I diabetes mellitus: a randomized open crossover trial. J Pediatr Endocrinol Metab. 2003;16(7):1047-50.

7. Fox LA, Buckloh LM, Smith SD, Wysocki T, Mauras N. A randomized controlled trial of insulin pump therapy in young children with type 1 diabetes. Diabetes Care. 2005;28(6):1277-81. 
8. Skogsberg L, Fors H, Hanas R, Chaplin JE, Lindman E, Skogsberg J. Improved treatment satisfaction but no difference in metabolic control when using continuous subcutaneous insulin infusion vs. multiple daily injections in children at onset of type 1 diabetes mellitus. Pediatr Diabetes. 2008;9(5):472-9.

9. Szypowska A, Schwandt A, Svensson J, Shalitin S, Cardona-Hernandez R,

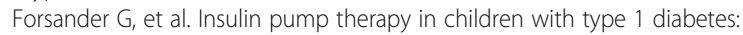
analysis of data from the SWEET registry. Pediatr Diabetes. 2016;17(October):38-45.

10. Lazar L, Fayman G, Lilos P, Dickerman Z, Phillip M. Daily injection regimens in children with type 1 diabetes. Pediatrics. 2003;112(3):559-64.

11. Wilson DM, Buckingham BA, Kunselman EL, Sullivan MM, Paguntalan HU, Gitelman SE. A two-center randomized controlled feasibility trial of insulin pump therapy in young children with diabetes. Diabetes Care. 2005;28(1):15-9.

12. DiMeglio LA, Pottorff TM, Boyd SR, France L, Fineberg N, Eugster EA. A randomized, controlled study of insulin pump therapy in diabetic preschoolers. J Pediatr. 2004;145(3):380-4.

13. Weintrob N, Benzaquen H, Galatzer A, Shalitin S, Lazar L, Fayman G, et al Comparison of continuous subcutaneous insulin infusion and multiple daily injection regimens in children with type 1 diabetes: a randomized open crossover trial. Pediatrics. 2003;112(3 Pt 1):559-64.

14. Pańkowska E, Błazik M, Dziechciarz P, Szypowska A, Szajewska H. Continuous subcutaneous insulin infusion vs. multiple daily injections in children with type 1 diabetes: a systematic review and meta-analysis of randomized control trials. Pediatr Diabetes. 2009;10(1):52-8.

15. Misso ML, Egberts KJ, PageM, O'Connor D, Shaw J. Continuous subcutaneous insulin infusion (CSII) versus multiple insulin injections for type 1 diabetes mellitus. Cochrane Database Syst Rev. 2010;(1):CD005103. https://doi.org/10.1002/14651858.CD005103.pub2

16. Benkhadra K, Alahdab F, Tamhane SU, McCoy RG, Prokop LJ, Murad MH. Continuous subcutaneous insulin infusion versus multiple daily injections in individuals with type 1 diabetes: a systematic review and meta-analysis. Endocrine. 2017;55(1):77-84.

17. Pickup JC, Sutton AJ. Severe hypoglycaemia and glycaemic control in type 1 diabetes: meta-analysis of multiple daily insulin injections compared with continuous subcutaneous insulin infusion. Diabet Med. 2008;25(7):765-74.

18. Chalew SA. The continuing challenge of outcome disparities in children with diabetes. Pediatrics. 2015;135(3):552-3.

19. Sherr JL, Hermann JM, Campbell F, Foster NC, Hofer SE, Allgrove J, et al. Use of insulin pump therapy in children and adolescents with type 1 diabetes and its impact on metabolic control: comparison of results from three large, transatlantic paediatric registries. Diabetologia. 2016;59(1):87-91.

20. Icks A, Razum O, Rosenbauer J, Bächle C, Hungele A, Mönkemöller K, et al. Lower frequency of insulin pump treatment in children and adolescents of Turkish background with type 1 diabetes: analysis of 21,497 patients in Germany. Diabetes Technol Ther. 2012;14(12):1105-9.

21. Marmot M, Friel S, Bell R, Houweling TA, Taylor S. Closing the gap in a generation: health equity through action on the social determinants of health. Lancet. 2008;372(9650):1661-9.

22. Chiang JL, Maahs DM, Garvey KC, Hood KK, Laffel LM, Weinzimer SA, et al. Type 1 diabetes in children and adolescents: a position statement by the American Diabetes Association. Diabetes Care. 2018;41(9):2026-44.

23. Rewers MJ, Pillay K, de Beaufort C, Craig ME, Hanas R, Acerini CL, et al. Assessment and monitoring of glycemic control in children and adolescents with diabetes. Pediatr Diabetes. 2014;15(SUPPL.20):102-14.

24. Shamseer L, Moher D, Clarke M, Ghersi D, Liberati A, Petticrew M, et al. Preferred reporting items for systematic review and meta-analysis protocols (prisma-p) 2015: elaboration and explanation. BMJ. 2015;350:g7647. [cited 2019 Apr 5].

25. Higgins JPT, Green S (editors). Chapter 4: Guide to the contents of a Cochrane protocol and review. In: Higgins JPT, Green S (editors). Cochrane Handbook for Systematic Reviews of Intervention. Version 5.1.0 [updated March 2011]. The Cochrane Collaboration, 2011. Available from www. cochrane-handbook.org.

26. Welch $V$, Petticrew M, Tugwell P, Moher D, O'Neill J, Waters E, et al. PRISMAEquity 2012 extension: reporting guidelines for systematic reviews with a focus on health equity. PLoS Med. 2012;9(10).

27. O'Neill J, Tabish H, Welch V, Petticrew M, Pottie K, Clarke M, et al. Applying an equity lens to interventions: using PROGRESS ensures consideration of socially stratifying factors to illuminate inequities in health. J Clin Epidemiol. 2014;67(1):56-64.
28. Ogilvie D, Fayter D, Petticrew M, Sowden A, Thomas S, Whitehead M, et al. The harvest plot: a method for synthesising evidence about the differential effects of interventions. BMC Med Res Methodol. 2008:8:1-7.

29. American Diabetes Association AD. Children and adolescents: standards of medical care in Diabetesd2018. Diabetes Care. 2018;41(Suppl 1):S126-36.

30. Ly TT, Maahs DM, Rewers A, Dunger D, Oduwole A, Jones TW. Assessment and management of hypoglycemia in children and adolescents with diabetes. Pediatr Diabetes. 2014;15(S20):180-92.

31. Zabar B. Diabetic ketoacidosis and hyperglycemic hyperosmolar state. Pract Emerg Resusc Crit Care. 2013;15:389-96.

32. Agiostratidou G, Anhalt H, Ball D, Blonde L, Gourgari E, Harriman KN, et al. Standardizing clinically meaningful outcome measures beyond $\mathrm{HbA1C}$ for type 1 diabetes: a consensus report of the American Association of Clinical Endocrinologists, the American Association of Diabetes Educators, the American Diabetes Association, the Endo. Diabetes Care. 2017:40(12):1622-30

33. Viswanathan M, Berkman ND, Dryden DM, Hartling L. Assessing risk of bias and confounding in observational studies of interventions or exposures: further development of the RTI Item Bank. 2013. Methods Research Report; 2013. Available from: www.effectivehealthcare.ahrq.gov/reports/final.cfm. Cited 2018 May 18

34. Higgins JPT, Altman DG, Sterne JA. Assessing risk of bias in included studies [Internet]. Chapter 8: Assessing risk of bias in included studies. Cochrane Handbook for Systematic Reviews of Interventions version 5.2.0 (updated June 2017); 2017. Available from: www.training.cochrane.org/handbook. Cited 2018 Sept 5

35. DerSimonian R, Kacker R. Random-effects model for meta-analysis of clinical trials: an update. Contemp Clin Trials. 2007;28(2):105-14.

36. Cohen J. In: Cohen J, editor. Statistical power analysis for the behavioral sciences. 2nd ed. Hillsdale: L. Erlbaum Associates; 1988. p. 19-66.

37. Higgins JPT, Thompson SG. Quantifying heterogeneity in a meta-analysis. Stat Med. 2002;21(11):1539-58.

38. Owens DK, Lohr K, Atkins D, Treadwell JR, Reston JT, Bass EB, et al. Methods guide for comparative effectiveness reviews: grading the strength of a body of evidence when comparing medical interventions [Internet]. Rockville, MD; 2008. Available from: http://effectivehealthcare.ahrq.gov/search-forguides-reviews-and-reports/?pageaction=displayproduct\&productID=1163. Cited 2018 Sep 6

39. Acerini $\mathbf{C}$. The rise of technology in diabetes care. Not all that is new is necessarily better. Pediatr Diabetes. 2016;17(3):168-73.

40. Burstin $\mathrm{H}$, Johnson K. Getting to better care and outcomes for diabetes through measurement. Am J Manag Care. 2016;22(Spec No. 4):SP145-6.

41. Welch V, Tugwell P, Petticrew M, de Montigny J, Ueffing E, Kristjansson B, McGowan J, Benkhalti Jandu M, Wells GA, Brand K, Smylie J. How effects on health equity are assessed in systematic reviews of interventions.Cochrane Database Syst Rev. 2010;(12):MR000028. https://doi.org/10.1002/14651858. MR000028.pub2

42. Sherr JL, Tauschman M, Battelino T, de Bock M, Forlenza G, Roman R, et al. ISPAD clinical practice consensus guidelines 2018 diabetes technologies. Pediatr Diabetes. 2018;19(July):302-25.

\section{Publisher's Note}

Springer Nature remains neutral with regard to jurisdictional claims in published maps and institutional affiliations.

Ready to submit your research? Choose BMC and benefit from:

- fast, convenient online submission

- thorough peer review by experienced researchers in your field

- rapid publication on acceptance

- support for research data, including large and complex data types

- gold Open Access which fosters wider collaboration and increased citations

- maximum visibility for your research: over $100 \mathrm{M}$ website views per year

At BMC, research is always in progress.

Learn more biomedcentral.com/submissions 